PRODUTO \& PRODUÇÃO, vol. 21, n.3, p.16-32. 2020

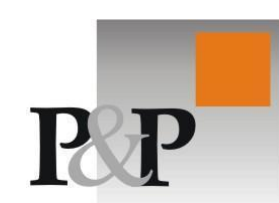

\title{
Análise Temporal da Tendência dos Registros de MEI por Competência
}

\author{
Temporal analysis of the trend of micro-entrepreneurs records by \\ competence
}

\author{
André Erichsen \\ Instituto Federal do Rio Grande do Sul, Brasil \\ e-mail: andreufrgs@hotmail.com \\ Vera Martins \\ Instituto Federal do Rio Grande do Sul, Brasil \\ e-mail:vera.martins@poa.ifrs.edu.br
}

\section{Resumo}

A promulgação das legislações de regularização de Microempreendedores Individuais no Brasil, suscitou aumento expressivo no registro formal destes, gerando postos de trabalho e renda para o erário público. Avaliar a tendência de crescimento, estimando o número de aberturas pode subsidiar a gestão pública, colaborando com a organização de serviços e associações de apoio às microempresas. Assim, este estudo analisa a tendência de formalização de Microempreendedores Individuais, visando identificar um modelo capaz de prever registros efetivados. Para tanto, utilizou-se o modelo $\operatorname{ARIMA}(\mathrm{p}, \mathrm{d}, \mathrm{q})$, que identificou tendência de crescimento sazonal e previsão para três passos à frente. As previsões para julho, agosto e setembro de 2019, indicaram 127.573, 146.606 e 128.075 registros, respectivamente. A tendência positiva observada está diretamente relacionada à redução da informalidade, possibilitando a adoção de medidas de fomento ao setor. Sugere-se que pesquisas futuras comparem o modelo apresentado a outros mais complexos, combinando diferentes informações para estimação da curva.

Palavras-chave: Tendência, ARIMA, Pequenas empresas.

Recebido em 24/01/2020. Aceito em 29/06/2020. 


\begin{abstract}
The enactment of regulation laws for individual entrepreneurs in Brazil led to a significant increase in these companies' registrations, generating jobs and income for the public purse. Assessing the growth trend, estimating the number of registrations can subsidize public management, collaborating with the organization of services and associations to support small businesses. Thus, this study analyzes the trend towards the Individual Microentrepreneurs formalization, aiming to identify a model capable of predicting useful records. This study uses the $\operatorname{ARIMA}(\mathrm{p}, \mathrm{d}, \mathrm{q})$ model, which identified a trend of seasonal growth and forecast for three steps ahead. Forecasts for July, August, and September 2019 indicated 127,573, 146,606, and 128,075 records, respectively. The positive trend observed is directly related to the reduction of informality, enabling the adoption of measures to promote the sector. As a suggestion, future research can compare the presented model to others of greater complexity, combining different information to estimate curves.
\end{abstract}

Keywords: Tendency, ARIMA, Small Business.

\title{
1. Introdução.
}

$\mathrm{Na}$ análise do cenário de desenvolvimento econômico, existem inúmeras áreas para as quais o governo deve dispor seus recursos financeiros e políticos a fim de que haja eficiência e eficácia para atingir os objetivos de gestão pública como liberação de crédito, implementação de políticas fiscais, entre outras. Bresser-Pereira (2008) relata que é objetivo político das sociedades modernas o desenvolvimento e o crescimento econômico (distinção que o autor não realiza entre essas palavras).

No Brasil, um grande problema fiscal para o governo é o da informalidade, tendo como consequência direta a menor arrecadação de impostos. Acrescenta Tiryaki (2008) que a informalidade causa variações nos ciclos econômicos, volatilizando a produção, investimentos e consumo, além de diminuir a arrecadação de impostos, além de, de modo geral, implicar em maiores esforços para estruturação e manutenção do plano de negócios. Portanto, a informalidade no mercado de trabalho é um dos problemas que deve ser dirimido. Para esse fim, o governo desenvolve políticas de fomento empresariais desde a década de 80, passando pela Lei Complementar $n^{\circ} 123 / 2006$, Estatuto Nacional das Microempresas e Empresas de Pequeno Porte e pela Lei Complementar n ${ }^{\circ}$ 128/2008, criadora do Microempreendedor Individual. Ademais a essas regulações, houve também a entrada em vigor de um novo código civil no exercício de 2002, atualizando, entre outros artigos, as disposições legais aplicáveis às pessoas jurídicas, impactando diretamente o mercado empresarial.

Costa e Leandro (2016) avaliaram o cenário econômico-financeiro das micro e pequenas empresas após a criação do Estatuto Nacional das Microempresas e Empresas de Pequeno Porte (Lei Complementar $n^{\circ}$ 123/2006). Por meio de uma pesquisa descritiva e documental, demonstram o cenário das micro e pequenas empresas para a época. Em seus resultados, o estudo indica que os pequenos negócios são importantes para o País, em especial pela geração de emprego e renda, e cresceram de modo substancial desde 2007, passando de 5.219.741 micro e pequenas empresas, para $14.812 .460 \mathrm{em}$ 2016.

Silva et al. (2017), apresenta em seu estudo que os principais motivos que levam um Microempreendedor Individual a comunicar a sua migração para microempresa são por infligir limite de funcionários ou de salário, mudança de atividades da empresa, abertura de filial, por opção, por participação em outra empresa, natureza jurídica vedada (inclusão de novo sócio) ou faturamento excedido de $\mathrm{R} \$ 60.000,00$ mensais. Behling e Lenzi (2016), identificaram quais fatores mais influenciaram decisão de formalização para MEI, por meio de uma pesquisa abrangendo 211 MEI do estado de Santa Catarina, a saber: segurança fiscal, a possibilidade de crescimento da empresa, a isenção 
de taxas para registro, possibilidade de vender para empresas, participar de licitações e receber apoio técnico. Agapito e Irigoyen (2017), identificam o perfil do Microempreendedor Individual dentro de um espaço temporal de 2009 a 2015. Neste estudo inferiram que 52,56\% são constituídas por homens, possuem idade média de 38,2 anos, sendo que $32,47 \%$ estão faixa de 31 a 40 anos, 23,75\% na faixa entre 41 e 50 anos, e $23,07 \%$ na faixa de 21 a 30 anos.

A literatura apresenta diferentes soluções e diagnósticos para as MEI, mas não abordam uma investigação na tendência de formalização destas por meio de registros oficiais. Assim, este estudo aborda a análise temporal dos registros de MEI por meio do modelo Autoregressive Integrated Moving Average (ARIMA ( $\mathrm{p}, \mathrm{d}, \mathrm{q})$ ), utilizando o Critério Informacional Baysiano (BIC) e a medida de acuracidade Mean Absolute Percentage Error (MAPE), tendo como subsídio as informações dos períodos de maio de 2013 a setembro de 2019, com o objetivo de identificar um modelo capaz de prever minimamente o número de registros passos à frente.

A relevância deste estudo está em analisar a tendência estatística do número de registros de MEI, visando com isto identificar um modelo capaz de prever o número de registros oficiais passos à frente. Este estudo se faz oportuno devido à expressiva diferença positiva entre aberturas e fechamentos de MEI no exercício de 2019, de janeiro até de setembro, no total de 1.291.712, e em funcionamento até essa competência, no total de 9.031.164, conforme dados do Portal do Empreendedor (2019), indicando a expansão de um mercado voltado para a formação de empreendedores.

A contribuição à gestão é denotada por este estudo no que tange ao planejamento de políticas públicas visando à diminuição da informalidade, à projeção de crescimento econômicos, ao incremento nas contribuições previdenciárias, ao desenvolvimento dos empreendedores, entre outros. Auxiliando com novas informações o debate público e posteriores modificações na legislação da MEI. A gestão governamental deste segmento empresarial torna-se essencial ao andamento das políticas públicas devido à grande preponderância das micro e pequenas empresas na economia. Conforme demonstra Romero (2019), em um estudo de maior abrangência geográfica, a estrutura empresarial na América Latina e na União Europeia apresenta o percentual de micro e pequenas empresas, no exercício de 2016, correspondente a $98 \%$ e $98,8 \%$

Por fim, a hipótese inicial deste trabalho é de que há uma tendência estatística positiva a qual pode ser utilizada para planejamento de políticas públicas futuras. Tem como limitação de escopo a reunião de informações e dados disponibilizados pelo governo brasileiro e sua posterior organização, não se aprofundando no estudo econômico das bases históricas das constituições das MEI, bem como não expondo ou analisando os benefícios e limitações concedidos pela lei do exercício de 2013 até 2019.

Este estudo está organizado da seguinte maneira: a seção inicial apresenta a introdução; a segunda seção, referencial teórico - apresentados o conceito de atividade do empresário no código civil, estudos sobre MEI, a situação das micro e pequenas empresas, os aspectos históricos e legislativos da MEI e, por fim, as ferramentas estatísticas; a terceira seção expõe os procedimentos metodológicos. Os resultados são divulgados nas seções seguintes, abordando a interpretação e análise dos dados, bem como as implicações para a gestão governamental e, a seção final, são expostas as considerações finais.

\section{Referencial Teórico.}

Esta seção compreende a relevância da atividade do empresário no Brasil, consubstanciada pelo Novo Código Civil, para os interesses dos participantes do mercado empresarial e do governo, para o qual o problema de pesquisa se aplica, bem como propõe-se a evidenciar em uma sucinta contextualização a situação das micro e pequenas empresas. Na sequência, discorre sobre os aspectos históricos da criação da MEI e de suas legislações principais, Lei Complementar no 123/2006 e Lei Complementar $\mathrm{n}^{\circ} 128 / 2008$, e acerca das ferramentas estatísticas utilizadas para análise. 


\subsection{Atividade do Empresário.}

Instituído pela lei $\mathrm{n}^{\circ}$ 10.406/2002, a partir do advento do Novo Código Civil foram reformuladas as normas que eram relativas ao âmbito do direito societário e empresarial, passando, desta forma, o Novo Código Civil a regular as relações jurídicas das empresas - cabe consignar a existência de muitos outros diplomas legais aplicáveis a aspectos específicos. No entanto, o ponto central do direito civil e comercial foi estabelecido, para todos os fins, no Novo Código Civil. Umas das modificações jurídicas mais impactantes foi a definição de empresário no artigo $n^{\circ} 966$ desta mesma lei, Brasil (2002): "Considera-se empresário quem exerce profissionalmente atividade econômica organizada para a produção ou circulação de bens ou serviços".

Todavia, o parágrafo único desse mesmo artigo, limita, Brasil (2002): "Não será considerado empresário aquele que exercer profissão intelectual de natureza científica, literária ou artística, mesmo se contar com o auxílio de colaboradores.". Esclarece esse ponto Coelho (2006) que os profissionais limitados pelo parágrafo único exploram, de fato, atividades econômicas civis, não sendo sujeitas à aplicação do direito empresarial. Continua o autor, citando que entre eles se encontram os profissionais liberais, tais como advogados, médicos, dentistas, arquitetos, entre outros, e os escritores e artistas de qualquer expressão tais como plásticos, músicos e atores.

\subsection{Micro e Pequenas Empresas.}

Ao final da década de 70 , iniciando a década de 80 , verificou-se que as micros e pequenas empresas estavam em expansão, adquirindo, assim, um papel cada vez mais importante na economia do país e no desenvolvimento social. Conforme Oliveira, et al. (2010), Julien (1997) e SEBRAE (2007) na década de 1970 teve o início da consolidação de um novo equilíbrio entre as empresas grandes e as pequenas em relação à importância econômica e social, tanto nos países em desenvolvimento quanto nos industrializados.

A partir desse crescimento, o governo federal envidou esforços a fim de criar um ambiente econômico-jurídico para fomentar essa expansão. Inicialmente realizado pela promulgação da lei $\mathrm{n}^{\circ}$ 7.256, de 27 de novembro de 1984, que estabeleceria no seu artigo $n^{\circ} 1$ Brasil (1984): "À microempresa é assegurado tratamento diferenciado, simplificado e favorecido, nos campos administrativo, tributário, previdenciário, trabalhista, creditício e de desenvolvimento empresarial, de acordo com o disposto nesta Lei”. 
Com o passar do tempo houve a necessidade de serem adotadas novas legislações abarcando as mudanças havidas nos meios econômico e social. Um dos resultados foi a promulgação da atual Lei Complementar $\mathrm{n}^{\mathrm{o}} 123$, de 14 de dezembro de 2006, a qual teve seu grande impacto, principalmente, na tributação das micro e pequenas empresas. Conforme Costa e Leandro (2016), a criação do Estatuto Nacional das Microempresas e Empresas de Pequeno Porte diminuiu as barreiras de criação das micro e pequenas empresas, estimulou o desenvolvimento da economia e a redução da informalidade.

De acordo com os dados divulgados pelo SEBRAE (2012), em 2012 aproximadamente 99\% das empresas em funcionamento no Brasil eram micro e pequenas empresas (MPE), correspondendo por aproximadamente 52\% dos empregos com carteira assinada no setor privado. Esses dados se mantêm estáveis durante o exercício de 2019, conforme demonstra a matéria "Pequenas empresas garantem saldo positivo de empregos, mostra Sebrae", Agência Brasil (2019). Consoante a esse dado, GEM-Brasil (2017), demonstra que no exercício de 2016, as MPE resultavam em 97,1\%. Após a criação da Lei Complementar $n^{\circ} 123 / 2006$, foi promulgada a Lei Complementar $n^{\circ} 128 / 2008$, criando a figura jurídica do Microempreendedor Individual, como forma de complemento de uma política pública de migrar os trabalhadores informais para a formalidade.

Essa nova figura jurídica permite que os trabalhadores possam se tornar empreendedores individuais, auferindo benefícios que outrora não possuíam. Conforme Agapito e Irigoyen (2017), alguns benefícios podem ser exemplificados pela formalização simplificada digital, isenção de impostos Federais, contribuição para o sistema de Seguridade Social, além de emissão de nota fiscal eletrônica, entre outros.

\subsection{Estatística Governamental.}

A utilização da estatística na esfera governamental tornasse necessária para a utilização eficiente dos recursos públicos devido ao grande número de dados e de informações disponíveis. A obtenção de previsões com maior acuracidade é uma necessidade constantemente requerida, já que há uma oferta imensa de dados e recursos computacionais cada dia mais eficientes, evidencia Martins (2014), resultando por fim um planejamento econômico e social que possua maior assertividade, eficácia e eficiência.

Ferreira (2003) comenta que a elaboração, o acompanhamento e a avaliação das ações governamentais devem ser subsidiados por informações estatísticas que, além de cobrir amplo escopo temático e territorial, necessitam ser atualizadas permanentemente. Conclui o autor que isso significa que não bastam informações censitárias atualizadas a cada dez anos: são necessárias atualizações constantes em um espaço temporal menor.

Ademais, Ferreira (2003) novamente cita a necessidade do uso da estatística pelo governo, pois a forma de atuação governamental tem implicado novas demandas por informações, a exemplo da chamada focalização das políticas sociais. Essas passam a eleger segmentos específicos da população como seu público-alvo, demandando informações detalhadas das características da população, o que inclui também suas demandas.

Nesse sentido, a estatística fornece ferramentas importantes para que os governos possam definir com mais assertividade suas metas, avaliar sua performance, identificar seus pontos fortes e fracos, atuando na melhoria contínua das políticas públicas, conforme explica Ignácio (2010). 


\subsubsection{Série-Temporal.}

As séries temporais são conjuntos de dados observados sequencialmente ao longo de um determinado tempo, sendo ordenados sucessivamente. Consubstanciando essa definição, Morettin e Toloi (2006) explana que uma série temporal é qualquer conjunto de observações ordenadas no tempo. Podemos destacar uma das características mais importantes desse tipo de dados: as observações vizinhas obtidas são dependentes linearmente ao longo do tempo que são observadas pelo sujeito, e o foco da análise de série temporal é analisar e posteriormente modelar essa dependência. Após essa modelagem, podem ser calculadas previsões $h$ passos à frente, conforme descreve Morettin e Toloi (2006).

Isso posto, os três objetivos de se realizar uma análise de série temporal em uma série de dados é: conjecturar previsões acerca do comportamento dos dados, analisar a estrutura em si da série ou a relação desta série com outra série. Os resultados obtidos dessa interpretação, conforme elenca Ehlers (2007) são:

- Descrição: propriedades da série, o padrão de tendência, existência de variação sazonal, outliers, alterações estruturais, entre outros;

- Explicação: usar a variação em uma série para explicar a variação em outra série e predição, predizer valores futuros com base em valores passados; e

- Controle de processos, controle estatístico de qualidade.

\subsubsection{Modelo ARIMA (p,d,q).}

Esse tipo de modelo foi descrito pelos autores Box e Jenkins em 1970 e caracterizam-se como uma das mais difundidas metodologias para análise de séries temporais (Morettin e Toloi, 2006). Conforme explica Eder (2011), a notação ARIMA (p, d, q) significa: "p", o número de termos da parte auto regressiva; "d", o número de diferenciações necessárias para tornar a série estacionária; "q", o número de termos da parte das médias móveis.

A metodologia proposta por Box e Jenkins é desenvolvida com base em três passos, conforme elenca Morettin e Toloi (2006):

- Identificação: com base na análise de autocorrelações, autocorrelações parciais e outros critérios, é identificado um modelo a ser utilizado;

- Estimação: os parâmetros do modelo identificado são estimados; e

- Verificação ou Diagnóstico: por meio de uma análise de resíduos, é verificado se o modelo identificado é adequado para o objetivo da análise.

Na primeira etapa, ocorre a identificação de os filtros que irão compor o modelo, em outras palavras, o número de componentes e a presença de médias móveis e autorregressivos identificados. Relata Jacobs, Zanini e Costa (2014) que é utilizada para esse fim a análise da função de autocorrelação parcial (FACP) e de autocorrelação (FAC). Encerra-se essa etapa quando ocorre a tomada de decisão a partir dos padrões identificados para as FACP e as FAC. 
Após conclusão da primeira etapa, o passo seguinte é a determinação do número de parâmetros "p" e "q" a serem adicionados. Esses parâmetros podem ser obtidos dos seguintes modos: FAC, FACP, critérios de Akaike, critério informacional de Akaike AIC ou, por fim, critério informacional Bayesiano (BIC). De acordo com Jacobs, Zanini e Costa (2014), escolhe-se aquele com o menor resultado dentre esses critérios, estimando-se após os parâmetros por meio dos métodos dos mínimos quadrados não lineares, dos mínimos quadrados ou da máxima verossimilhança.

Na terceira etapa, no entendimento de Werner e Ribeiro (2003), realiza-se a verificação por meio da análise de resíduos, na qual os resíduos do modelo serão do tipo branco (ou seja, os coeficientes de autocorrelação dos resíduos devem ser estatisticamente iguais a zero), e por meio da avaliação de ordem do modelo. Para fins de aplicação do Modelo ARIMA (p, d, q), foi utilizado o software estatístico Statistical Package for the Social Sciences ${ }^{\circledR}\left(\right.$ SPSS $\left.^{\circledR}\right)$ v.22. Neste estudo foi esse o modelo escolhido, pois, explana Borgatto (2000) que o modelo ARIMA (p, d, q) é um modelo adequado para tratamento estatístico desses tipos de dados.

\section{Procedimentos Metodológicos.}

Para a abordagem do problema, este estudo é classificado como quantitativo, devido à utilização de coleta e tratamento das informações e tratamento estatístico. O número de MEI registradas por competência desde maio de 2013 até setembro de 2019 será obtido por meio de análises quantitativas.

Quanto aos objetivos, este estudo é classificado como descritivo, pois, de acordo com Cervo e Bervian (1996), este tipo de pesquisa procura encontrar a frequência com que um fenômeno ocorre, sua relação e conexão com outros, sua natureza e características, correlacionando fatos ou fenômenos sem, todavia, manipulá-los. Por fim, este estudo é classificado como ex post facto, devido aos procedimentos técnicos utilizados, já que a metodologia adotada neste estudo é a utilização de documentos de fontes secundárias com vistas à utilização de dados, informações e evidências, que não tenham sido objeto de análise ou que serão analisados com outra ótica de pesquisa, conforme Martins e Theóphilo (2009).

A população em estudo é composta pelo número de registros de MEI durante o período de maio de 2013 a setembro de 2019, período justificado pela abrangência temporal de seis exercícios, dentro dos quais 77 competências foram evidenciadas, além do amadurecimento e estabilização do crescimento vegetativo das aberturas de MEI, e, por fim, pelo fechamento de 3 trimestres do exercício final de 2019 com os dados já consolidados, não havendo posterior retificação, findo o exercício de 2019. A coleta de dados e de informações, realizada na competência de outubro de 2019, foi originária do sítio eletrônico do Portal do Empreendedor (2019), bem como do sítio eletrônico do Planalto (2019) visto que esses dados e informações estão disponibilizados ao público em geral.

As etapas do tratamento das informações e dos dados possuem a seguinte ordem:

I. Reunir e tabular os dados de MEI registradas por competência:

A coleta do número de MEI registradas foi realizada no sítio eletrônico Portal do Empreendedor. Os dados coletados do número de MEI registradas foram relativos ao último dia disponibilizado no sítio eletrônico da competência de cada competência e por fim, foi realizada a subtração das MEI registradas entre as competências para se verificar a variação do número de MEI dentro da competência.

II. Realizar tratamento estatístico dos dados obtidos, por meio da função expert do software SPSS $^{\circledR}$ para modelos ARIMA sazonais, utilizando o modelo ARIMA (p, d, q) (P, D, Q);

III. Verificar se o modelo proposto se mostrou adequado nas previsões de registros de MEI das competências de julho, agosto e setembro de 2019 através do MAPE calculado.

IV. Analisar as implicações dos resultados para a gestão governamental. 
O MAPE é utilizado para mensurar o desempenho da série histórica, expressando a precisão do erro em percentagem, ou seja, tem como objetivo de quantificar a magnitude do erro obtido em relação à série histórica. O MAPE é considerado uma das medidas mais consolidadas para seleção de modelos de séries temporais (Martins e Werner, 2012; Goodwin e Lawton, 1999). De acordo com Camelo et al. (2017), a grande vantagem de utilizar essa expressão está na sua representação em termos percentuais, a qual fornece um rápido entendimento. O MAPE pode ser obtido conforme Equação 1.

$$
M A P E=\frac{\sum_{1}^{n} a b s\left(\frac{y_{t}-\hat{y}_{t}}{y_{t}}\right)}{n} * 100 \%
$$

Onde: " $\mathrm{y}_{\mathrm{t}}$ " é o valor observado no tempo t, " $\hat{y}_{t}$ " é o valor previsto para o tempo te "n" é o número de observações quantificadas. O resultado dessa equação indica que quanto mais próximo de 0 (zero) for o resultado, tanto mais fidedigna é a análise.

\section{Análise dos Dados.}

Os dados analisados neste estudo são referentes ao número de registros de MEI, observados no Portal do Empreendedor, na Figura 1, é possível observar o número crescente de MEI registradas ao longo do espaço temporal analisado, iniciando pela competência de maio de 2013 até a competência de setembro de 2019. Para fins de evidenciação, na competência de maio de 2013 estavam registradas 3.065.628 MEI e na competência de setembro de 2019 estavam registradas 9.031.164 MEI, denotando um aumento de $194,59 \%$.



Figura 1 - Número de MEI Registradas

Fonte: Elaborado pelos Autores (2019) 
A Figura 2 apresenta a diferença entre o número de MEI registradas e fechadas por competência de junho de 2013 até setembro de 2019. De acordo com a Figura 2, a diferença entre a aberturas e o fechamento de MEI sempre resulta no acréscimo mensal de MEI. Todavia há um evento de exceção na competência de fevereiro. Nessa competência houve uma operação da Receita Federal do Brasil (RFB) - por meio do Ato Declaratório Executivo COCAD nº 1 , de fevereiro de 2018 - para a baixa de CNPJ de MEI, totalizando 1.372.246 baixas, (Receita Federal do Brasil, 2018). Esses CNPJ são referentes a contribuintes intimados em outubro de 2017 que não regularizaram a sua situação até 26 de janeiro de 2018. Tal evento resultou em uma quebra na série histórica impactando diretamente a elaboração de modelos matemáticos que não utilizam ajuste neste ponto.

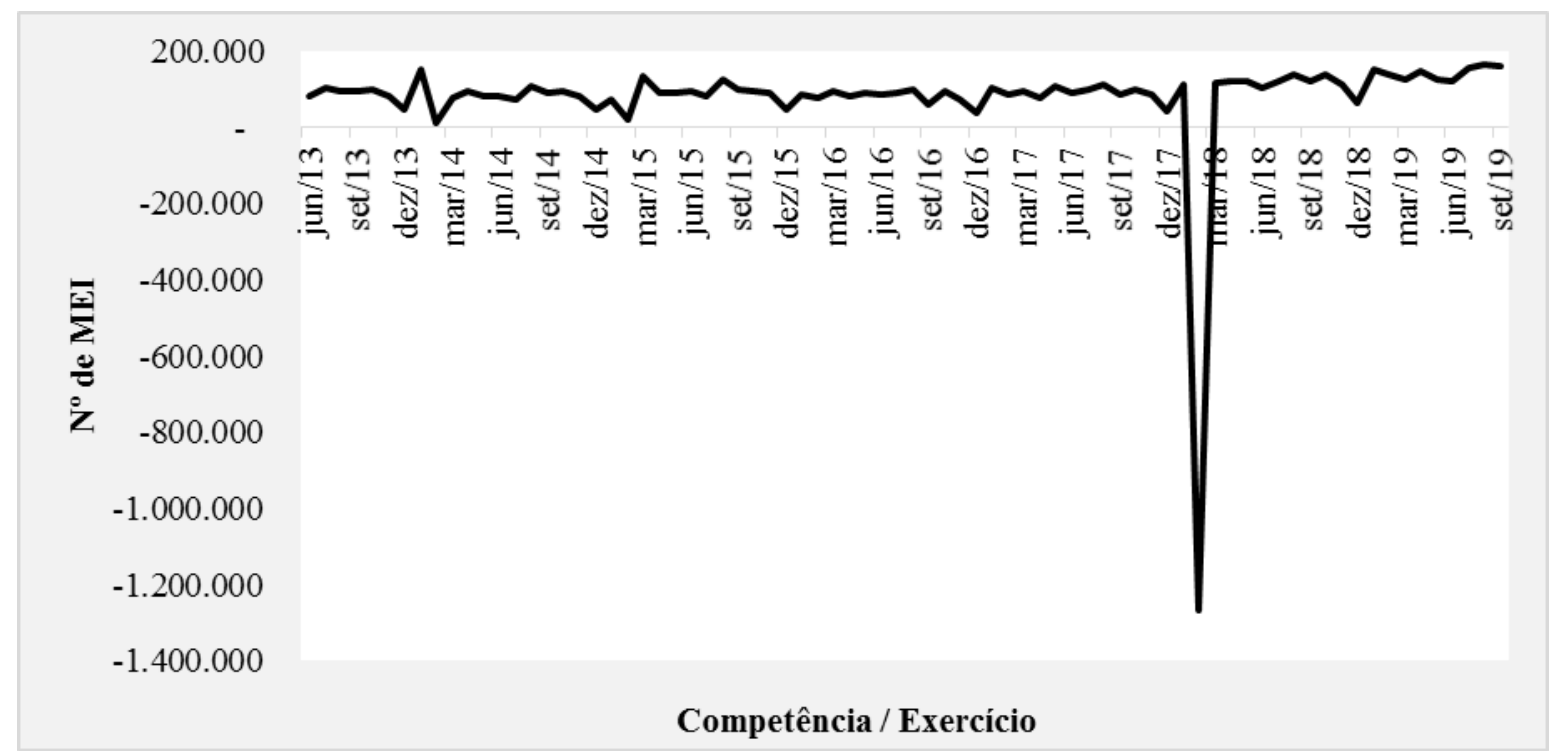

Figura 2 - Diferença entre Aberturas e Fechamentos de MEI Fonte: Elaborados pelo Autores (2019)

Devido à operação da Receita Federal do Brasil na competência de fevereiro de 2018, resultando na baixa de CNPJ, o dado da competência de fevereiro de 2018 foi avaliado como outlier na modelagem estatística por se tratar de um evento de exceção e, portanto, considerado nulo.

A modelagem ARIMA ( $p, d, q$ ), foi utilizada neste estudo com o intuito de verificar o comportamento da tendência, utilizando para seleção do modelo mais adequado a medida de acuracidade MAPE e o critério informacional BIC. Assim, o modelo de melhor ajuste indicado foi o ARIMA $(0,0,0)(0,1,0)$, selecionado de acordo com a medida calculada MAPE e BIC normalizado de 18,275 e 20,700 , respectivamente. Para fins de consolidação do modelo, foi calculado o MAPE para as previsões das competências de julho, agosto e setembro de 2019, resultando em um MAPE de 16,256, ainda mais ajustado que a série modelada. Desta forma, em comparação ao MAPE calculado do modelo, o MAPE das previsões está menor, evidenciando que o modelo se mostrou adequado, podendo assim, ser utilizado para fins de planejamento de políticas públicas. A Figura 3 apresenta o comparativo entre a diferença de número de aberturas e fechamentos de MEI e as previsões realizadas pelo modelo. 


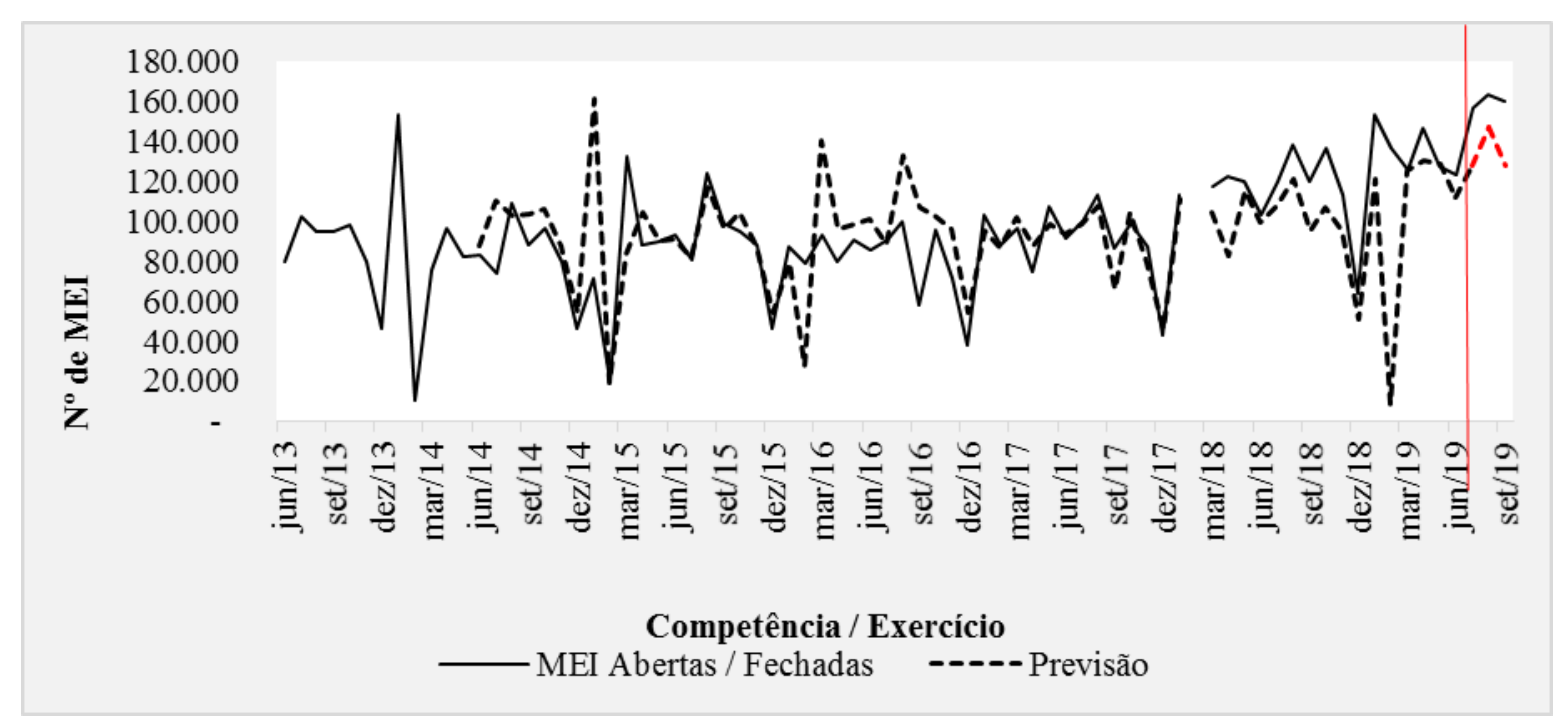

Figura 3 - Aberturas x Previsão Estatística

Fonte: Elaborado pelo Autor (2019)

Na Figura 3 é possível identificar que, a partir de dezembro de 2016, a previsão realizada e os dados observados apresentam poucos resíduos apesar da quebra observada em fevereiro de 2019. A falta de acuracidade neste ponto pode ser explicada pelo aumento do valor da guia de recolhimento da MEI de $6,47 \%$ em relação à parcela da Contribuição para a Seguridade Social, conforme base de cálculo estabelecida na resolução CGSN Nº140/2018 (Brasil, 2018), subsidiada pela portaria MF No 8/2017 (Brasil, 2017). A Tabela 1 apresenta o resultado do processamento dos dados apresentados para a previsão do trimestre das competências de julho, agosto e setembro de 2019:

Tabela 1 - Modelo ARIMA $(0,0,0)(0,1,0)$

\begin{tabular}{l|r|r|r}
\hline ARIMA & jul/19 & ago/19 & \multicolumn{1}{c}{ set/19 } \\
\hline Dados Observados & 156.959 & 163.428 & 159.600 \\
Previsão & 127.573 & 146.606 & 128.075 \\
Resíduos & 29.386 & 16.822 & 31.525 \\
\hline
\end{tabular}

Fonte: Elaborado pelos autores (2019)

Conforme exposto anteriormente, o dado da competência de fevereiro de 2018 foi avaliado como outlier na modelagem estatística, por se tratar de um evento de exceção, e, portanto, considerado nulo na análise. Para fins de demonstração, foi retirado da Figura 3.

\section{Implicações para a Gestão Governamental.}

A partir deste modelo, é possível inferir sobre a projeção dos registros de MEI. A projeção positiva pode ser diretamente relacionada a diminuição da informalidade, trazendo a um segmento da sociedade o benefício de direitos, tal como, aposentadoria, mediante o aumentando da arrecadação ao erário público, a qual, em parte, seria um incremento nas contribuições previdenciárias. Ademais, há a 
facilitação para o acesso ao crédito pelas MEI, por meio de empréstimos e financiamentos diretos ou indiretos, realizados por meio de linhas de crédito governamentais, ferramenta importante que o governo utiliza para administrar a economia, facilitando o aquecimento da economia em momentos de crise e homogeneizando o benefício e os resultados em diversos setores.

De modo geral, o governo pode projetar o crescimento econômico desse segmento empresarial, empenhando esforços para implementar políticas públicas eficientes e eficazes para beneficiamento destes. Neste contexto, a informalidade pode prejudicar substancialmente a capacidade de gestão, dificultando-a, pois com a diminuição da entrada de recursos tanto com destinação previdenciária quanto com destinação na forma de investimento, manutenção ou pagamento de vencimentos do funcionalismo público, menor é a capacidade do governo de, por exemplo, se preparar para uma crise, realizar e planejar obras de infraestrutura e programas sociais e, de modo geral, investimentos intangíveis os quais surtirão efeitos futuramente, como a educação, por exemplo.

O fomento ao empreendedorismo, segundo Porter (1993) contribui de forma positiva para o desenvolvimento econômico já que introduz inovação tanto na forma de novos produtos processos de produtivos, desta forma, levando a competividade e ao aumento da eficiência econômica.Com o aumento da disponibilidade de produtos, processos produtivos e serviços, aumenta-se gradativamente o consumo destes, aquecendo a economia, e, assim, disponibilizando à gestão governamental, subsídios, não só na forma de recursos financeiros, mas também tecnológicos, meios para que ela possa se fazer eficaz e eficiente.

Em relação às atividades abrangidas pela MEI, o aumento do leque de atividade sujeitas a este regime para abranger mais atividades informais ou que estão sendo exercidas informalmente, trazendo o trabalhador à formalidade, traz benefícios tanto a pessoa, quanto ao governo, no que tange a arrecadação principalmente. A sua contrapartida é igualmente verdadeira, pois a exclusão de atividades abrangidas pela MEI pode afetar de modo substancial a capacidade de recolhimento ao erário público e, desta forma, a capacidade de gestão do governo. Em notícia recente, na competência de dezembro de 2019, o Comitê Gestor do Simples Nacional aprovou a resolução CGSN nº 151 que revogou as exclusões que a resolução CGSN n ${ }^{\circ} 150$ havia realizado de atividades enquadradas como MEI (DOU, 2019). Caso a referida resolução não fosse revogada, haveria uma perda imediata para janeiro de 2020 de 615.091 MEI e, consequentemente, de um montante de $\mathrm{R} \$ 33.718 .752$ mensais e $\mathrm{R} \$ 404.625 .023$ anuais em arrecadação.

\section{Considerações Finais.}

Este estudo teve como objeto verificar a tendência estatística do número de registos das MEI por competência, visando com isto identificar um modelo capaz de prever minimamente o número de registros passos à frente. Para este fim, foram analisados os números de registros de MEI por competência, coletados durante o exercício de 2019, referentes ao período de maio de 2013 até setembro de 2019.

A previsão da tendência para a abertura das MEI traz contribuições, agregando mais informações, ao rol de iniciativas na gestão governamental, no que tange, principalmente, à projeção do superávit ou déficit previdenciário, ao planejamento de obras em infraestrutura e a continuidade e manutenção do funcionalismo público e suas instituições. Por certo, a importância em realizar essa análise recai, e sua importância para a gestão governamental, sob fato do grande espaço ocupado pelas micro e pequenas empresas na estrutura empresarial, SEBRAE (2012), GEM-Brasil (2017) e Romero (2019). Desta forma, a gestão governamental eficiente e eficaz desse segmento é um processo e uma etapa importante no crescimento e estabilização da economia e sociedade. Ademais, conforme informativo de a Organização Mundial do Comércio (2016), esta segrega e padroniza a caracterização desse segmento, inclusive utilizando indicadores nacionais para cada país. Tem como limitação de escopo a reunião de informações e dados disponibilizados pelo governo brasileiro e sua posterior organização, não se 
aprofundando no estudo econômico das bases históricas das constituições das MEI, bem como não expondo ou analisando os benefícios e limitações concedidos pela lei dos exercícios de 2013 até 2019.

Após a modelagem estatística, verificou-se que o modelo ARIMA $(0,0,0)(0,1,0)$ foi o melhor modelo indicado, possuindo a medida calculada MAPE de 18,275 e o critério informacional BIC normalizado de 20,700. Ademais, o resultado do cálculo do MAPE das previsões das competências de julho, agosto e setembro de 2019 resultou menor do que o MAPE calculado do modelo, totalizando 16,265. Esse resultado evidencia que o modelo está adequado, todavia sendo necessária a sua revisão para reavaliar os parâmetros propostos e posterior inclusão de mais dados. Desta forma, o modelo pode ser utilizado para fins de planejamento de políticas públicas visando à diminuição da informalidade, à projeção de crescimento econômicos e ao incremento nas contribuições previdenciárias da MEI.

Pesquisas futuras poderão abranger um maior espaço temporal de dados, bem como utilizar outros modelos. Outros estudos podem utilizar outras variáveis quantitativas e testar sua correlação estatística com número de registros de MEI, por meio, por exemplo, da análise de regressão linear. Por fim, pode ser investigada em futuras análises se há impacto nesse número quando da mudança da legislação que rege a MEI.

\section{Referências.}

AGAPITO, E.R; IRIGOYEN, N.B. Política Pública do Microempreendedor Individual: Perfil e Evolução Histórica. 2017. 14 f. Trabalho de Conclusão de Curso (Bacharelado em Administração Pública) - Universidade Federal Fluminense, Niterói, 2017. Disponível em: https://app.uff.br/riuff/bitstream/1/5345/1/Esthefani\%20Ribeiro\%20-\%20Nicolas\%20Barco.pdf.

Acesso em: 11 set. 2019.

AGENCIA BRASIL. Pequenas empresas garantem saldo positivo de empregos, mostra Sebrae. Disponível em: http://agenciabrasil.ebc.com.br/educacao/noticia/2019-07/pequenas-empresasgarantem-saldo-positivo-de-empregos-mostra-sebrae. Acesso em: 16 nov. 2019.

BEHLING, G; LENZI, F.C. Você É MEI? Porque? Uma Análise dos Influenciadores da Decisão de Formalização de Microempreendedores Individuais (MEI). In: IX ENCONTRO DE ESTUDOS SOBRE EMPREENDEDORISMO E GESTÃO DE PEQUENAS EMPRESAS, 2016, Passo Fundo. Disponível em: http://www.egepe.org.br/2016/artigos-egepe/182.pdf. Acesso em: 11 set. 2019.

BRASIL. Presidência da República. Lei 7.256, de 27 de novembro de 1984. Estabelece Normas Integrantes do Estatuto da Microempresa, Relativas ao Tratamento Diferenciado, Simplificado e Favorecido, nos Campos Administrativo, Tributário, Previdenciário, Trabalhista, Creditício e de Desenvolvimento Empresarial. Disponível em: http://www. planalto.gov.br/ccivil_03/leis/L7256.htm. Acesso em: 20 set. 2019.

BRASIL. Presidência da República. Lei 10.406, de 10 de janeiro de 2002. Institui o Código Civil. Disponível em: http://www.planalto.gov.br/ccivil_03/LEIS/2002/L10406.htm. Acesso em: 20 de setembro 2019.

BRASIL. Presidência da República. MF nº8, de 13 de janeiro de 2017. Dispõe sobre o reajuste dos benefícios pagos pelo Instituto Nacional do Seguro Social - INSS e dos demais valores constantes do Regulamento da Previdência Social - RPS. Disponível em: http://normas.receita.fazenda.gov.br/sijut2consulta/link.action?visao=anotado\&idAto=79662. Acesso em: 08 maio 2020.

BRASIL. Presidência da República. Resolução CGSN nº140, de 22 de maio de 2018. Dispõe sobre o Regime Especial Unificado de Arrecadação de Tributos e Contribuições devidos pelas Microempresas e Empresas de Pequeno Porte (Simples Nacional). Disponível em: 
http://normas.receita.fazenda.gov.br/sijut2consulta/link.action?visao=anotado\&idAto $=92278$. Acesso em: 08 de maio 2020.

BRESSER-PEREIRA, L. C. O Conceito histórico de desenvolvimento econômico. Disponível em: www.bresserpereira.org.br/papers/2008/08.18.ConceitoHistóricoDesenvolvimento.31.5.pdf.Acesso em: 17 out.de 2019 .

BORGATTO, A. F. Análise de Intervenção em Séries Temporais: Aplicação em Transporte Urbano. Dissertação (Mestrado em Agronomia). Faculdade de Agronomia, Universidade Federal de Lavras, Lavras, 2000.2 Disponível em: http://repositorio.ufla.br/jspui/bitstream/1/15569/1/DISSERTA\%C3\%87\%C3\%83O_An\%C3\%A1lise \%20de\%20interven\%C3\%A7\% C3\%A3o\%20em\%20s\%C3\%A9ries\%20temporais\%3A\%20aplica\%C 3\%A7\%C3\%B5es\%20em\%20transporte\%20urbano.pdf. Acesso em: 15 nov. 2019.

CAMELO, H. N.; LUCIO, P. S.; JUNIOR, J. B. V. L.; CARVALHO, P. C. M.; Métodos de Previsão de Séries Temporais e Modelagem Híbrida ambos Aplicados em Médias Mensais de Velocidade do Vento para Regiões do Nordeste do Brasil. Revista Brasileira de Meteorologia, v. 32, n. 4, p. 565-574, Mar. 2017. Disponível em: http://www.scielo.br/pdf/rbmet/v32n4/0102-7786-rbmet-32-04-0565.pdf. Acesso em: 22 nov. 2019.

CERVO, A; BERVIAN, P. A. Metodologia Científica. 4. ed. São Paulo: Makron Books, 1996.

COELHO, F. U. Curso de direito comercial. 17ª ed. São Paulo: Saraiva, 2006.

COSTA, A. P. N.; LEANDRO, L. A. L. O atual cenário das micro e pequenas empresas no Brasil. In: XIII Simpósio de Excelência em Gestão e Tecnologia, Rio de Janeiro, 2016. Disponível em: https:// www.aedb.br/seget/arquivos/artigos16/14924134.pdf. Acesso em: 16 set. 2019.

DOU. Diário Oficial da União: Resolução No 151, De 11 De Dezembro De 2019. Disponível em: http://www.in.gov.br/en/web/dou/-/resolucao-n-151-de-11-de-dezembro-de-2019-232940404. Acesso em: 11 dez. 2019.

EDER, K. Aplicação de Metodologias para Análise e Previsão do Preço do Fruto de Açaí. Dissertação (Mestrado em Biotecnologia). Faculdade de Biotecnologia, Universidade Federal de São Carlos, São Carlos, $2011 . \quad$ Disponível em: https://repositorio.ufscar.br/bitstream/handle/ufscar/6991/3991.pdf?sequence=1\&isAllowed=y Acesso em: 17 nov. 2019.

EHLERS, R. S. Análise de Séries Temporais. Laboratório de Estatística e Geoinformação Universidade Federal do Paraná, Departamento de Estatística, UFPR, 2007. Disponível em: http://www.each.usp.br/rvicente/AnaliseDeSeriesTemporais.pdf. Acesso em: 15 nov. 2019.

EMILIANO, P. C. Fundamentos e Aplicações dos Critérios de Informação: AKAIKE e Bayesiano. Dissertação (Mestrado em Estatística). Pós-Graduação em Estatística e Experimentação Agropecuária, Universidade Federal de Lavras, Lavras, 2009. Disponível em: http://repositorio.ufla.br/jspui/bitstream/1/3636/1/DISSERTA\%C3\%87\%C3\%83O_Fundamentos\%20 e\%20Aplica\%C3\%A7\%C3\%B5es\%20dos\%20Crit\%C3\%A9rios\%20de\%20Informa\%C3\%A7\%C3\% A3o\%20Akaike\%20e\%20Bayesiano.pdf. Acesso em: 15 nov. 2019.

FERREIRA, S. P. Produção e disponibilização de estatísticas: uma abordagem institucional. São Paulo Perspectiva, São Paulo: SEADE, v.17, n.3-4, p.17-25, dez. 2003. Disponível em: http://www.scielo.br/scielo.php?script=sci_arttext\&pid=S0102-88392003000300003. Acesso em: 14 nov. 2019. 
GEM-BRASIL. Global Entrepreneurship Monitor: Empreendedorismo no Brasil 2016. Curitiba: IBQP. 2017. Disponível em: http://ibqp.org.br/wp-content/uploads/2017/07/AF-GEM-Nacional-BAIXA.pdf. Acesso em: 08 maio 2020.

GOODWIN, P., LAWTON, R. On the asymmetry of the symmetric MAPE. International Journal of Forecasting, 15, 405-408, 1999.

JACOBS, W.; ZANINI, R. R.; COSTA, M. Estudo Comparativo De Séries Temporais Para Previsão De Vendas De Um Produto. Revista Iberoamericana de Engenharia Industrial, v. 6, n. 12, p. 112-33, Out. 2014. Disponível em: http://incubadora.periodicos.ufsc.br/index.php/IJIE/article/view/2599. Acesso em: 06 nov. 2019.

JULIEN, P. A. Les PME: bilan et perspective. Quebec: Les Presses Inteer Universitaires, 1997.

IGNACIO, S. A. Importância da Estatística para o Processo de Conhecimento e Tomada de Decisão. Revista Paranaense de Desenvolvimento, n.118, p. 175-192, 2010. Disponível em: https://dialnet.unirioja.es/servlet/articulo?codigo=4813262. Acesso em: 12 de nov. 2019.

MARTINS, G. A.; THEÓPHILO, C. R. Metodologia da Investigação Científica para Ciências Sociais Aplicadas. 2 ed. São Paulo: Atlas, 2009.

MARTINS, V. L. M. Combinação de Previsões: Uma Proposta Utilizando Análise de Componentes Parciais. Tese (Doutorado em Engenharia). Pós-Graduação em Engenharia de Produção, Universidade Federal do Rio Grande do Sul, Porto Alegre, 2014. Disponível em: https://www.lume.ufrgs.br/bitstream/handle/10183/109140/000949419.pdf?sequence=1\&isAllowed=y . Acesso em: 10 nov. 2019.

MARTINS, V. L. M; WERNER L. Expert Systems with Applications 39 (2012) 11479-11486. Doi: http://dx.doi.org/10.1016/j.eswa.2012.04.007

MORETTIN, P. A.; TOLOI, C. M. C. Análise de séries temporais. 2 ed. rev. ampl. São Paulo: Edgard Blücher, 2006.2 Disponível em: https://issuu.com/editorablucher/docs/issuu_analise_temporais_isbn9788521203896. Acesso em: 22 nov. 2019.

OLIVEIRA, J.; TERRENCE, A. C. F.; FILHO, E. E. Planejamento Estratégico e Operacional na Pequena Empresa: impactos da formalização no desempenho e diferenças setoriais. Revista Gestão Organizacional, v.3, n.1, jan. 2010. Disponível em: https://bell.unochapeco.edu.br/revistas/index.php/rgo/article/view/654/418. Acesso em: 23 nov. 2019.

Organizacão Mundial Do Comércio. Informe sobre el comercio mundial 2016: Igualdad de condiciones para el comercio de las pymes. Disponível em: https://www.wto.org/spanish/res_s/booksp_s/world_trade_report16_s.pdf. Acesso em: 08 de maio 2020.

PLANALTO. Presidência da República Brasil. Disponível em: http://www2.planalto.gov.br/. Acesso em: 20 set. 2019.

PORTAL DO EMPREENDEDOR. Portal do Empreendedor - MEI. Disponível em: http://www.portaldoempreendedor.gov.br/. Acesso em: 07 nov. 2019.

PORTER, M. E. A vantagem competitiva das nações. Rio de Janeiro: Campus,1993

RECEITA FEDERAL DO BRASIL. Receita divulga relação de baixa de CNPJs - MEI. Disponível em: https://receita.economia.gov.br/noticias/ascom/2018/fevereiro/receita-divulga-relacao-de-baixa-decnpjs-do-mei. Acesso em: 12 nov. 2019. 
ROMERO, R. J. G. Prospectiva e inteligencia estratégica aplicada a la micro, pequeña y mediana empresa. Revista de la Facultad de Ciencias Económicas y Administrativas, México, v. XX, n. 1, 2019. Disponível em: http://www.scielo.org.co/pdf/tend/v20n1/2539-0554-tend-20-01-00107.pdf. Acesso em: 08 maio 2020

SEBRAE. Fatores condicionantes e taxa de mortalidade das MPE. Pesquisa elaborada pelo Instituto Vox Populi, v. III, 2007. Disponível em: http://www.bibliotecas.sebrae.com.br/chronus/ARQUIVOS_CHRONUS/bds/bds.nsf/8F5BDE79736C B99483257447006CBAD3/\$File/NT00037936.pdf. Acesso em: 25 nov. 2019.

SEBRAE. Pequenos Negócios em Números. Disponível em: https://www. sebrae.com.br/sites/PortalSebrae/ufs/sp/sebraeaz/pequenos-negocios-emnumeros,12e8794363447510VgnVCM1000004c00210aRCRD. Acesso em: 16 set. 2019.

SILVA, P.S.S; ALVES, S.A.S; SILVA, T.T; RIZZO, M.R; ATHAYDE, T.R. Microempreendedor Individual e Seus Aspectos de Transição. Revista Magistro, Rio de Janeiro, v. 1, n. 15, 2017. Disponível em: http://publicacoes.unigranrio.edu.br/index.php/magistro/article/view/4012. Acesso em: 20 set. 2019.

TIRYAKI, G. F. A Informalidade E As Flutuações Na Atividade Econômica. Estud. Econ., São Paulo, v. 38, n. 1, p. 97-125, Mar. 2008. Disponível em: http://www.scielo.br/pdf/ee/v38n1/05. Acesso em: 18 nov. 2019.

WERNER, L.; RIBEIRO, J. L. D. Previsão De Demanda: Uma Aplicação Dos Modelos Box-Jenkins Na Área De Assistência Técnica De Computadores Pessoais. Gestão \& Produção, São Carlos, v. 10, n. 1, 2003. Disponível em: http://www.scielo.br/scielo.php?script=sci_arttext\&pid=S0104530X2003000100005. Acesso em: 09 nov. 2019. 